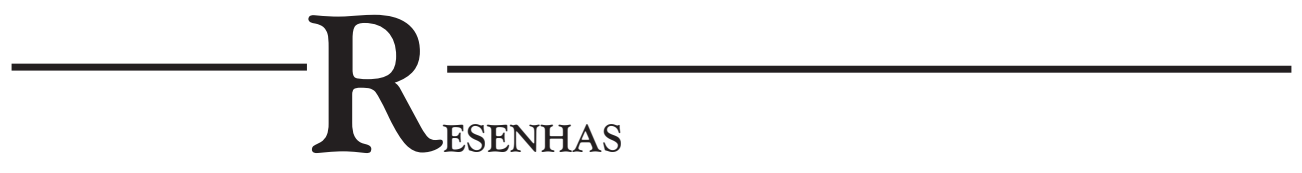

MONTERO, Paula (Org.). Religiões e controvérsias públicas: experiências, práticas sociais e discursos. São Paulo: Editora Unicamp; Terceiro Nome, 2015, $343 \mathrm{pp}$.

\title{
Controvérsia, UM MANDAMENTO NOVO?
}

Júlio Bizarria

Universidade Federal do Estado do Rio de Janeiro - Rio de Janeiro Rio de Janeiro - Brasil

A obra Religiões e controvérsias públicas, experiências, práticas sociais e discursos reúne resultados de pesquisas albergadas sob projeto homônimo, desenvolvido entre 2011 e 2014, com apoio da Fundação de Amparo à Pesquisa do Estado de São Paulo. Os trabalhos oferecem uma pluralidade de olhares sobre a nova conformação da sociabilidade democrática, transformada pelo contato entre o campo religioso e uma esfera pública constituída, justamente, na deriva que afastou o Estado nacional e a Igreja Católica, que afrontou a hegemonia desta de maneira consistente a partir dos anos 1980.

Isso possui consequências importantes na maneira como os diferentes atores políticos e grupos religiosos se apresentam na esfera pública brasileira: por um lado, 
insinuam-se sobre espaços outrora ocupados pela Igreja Católica; por outro, agem no âmbito de uma democracia liberal que lhes impõe a objetivação e a relativização de suas posições, sua justificação diante de uma opinião pública secular. $\bigcirc$ resultado não é apenas o de um debate, à maneira de Habermas, mas de uma ocupação da esfera pública pela via de confrontações cuja regulação é concomitante a seu próprio desenvolvimento: organizar esses desacordos a partir de ocasiões de controvérsia pública torna-se uma regra implícita dessa nova sociabilidade e, paralelemente, uma chave relevante para seu estudo.

Os dois primeiros estudos apresentam-se complementares. Eduardo Dullo, no contexto das eleições de 2012 para a prefeitura da cidade de São Paulo, explora os significados de acusações, provenientes do meio católico, de que o Partido Republicano Brasileiro (PRB) e seu candidato, Celso Russomano, seriam "braços políticos" da Igreja Universal do Reino de Deus, atentando contra as bases do secularismo. Estes, defendendo-se, ressignificavam a categoria intolerância religiosa, da qual acusavam a Igreja Católica. Esta, conclui Dullo, assumiria uma "posição bifronte": era-lhe conveniente defender os termos de um secularismo no qual mantivesse residual hegemonia, opção que não estaria disponível à IURD, donde seu envolvimento ativo na política partidária. O texto de Carlos Gutierrez, a partir das controvérsias surgidas em torno da participação de membros da Força Jovem Universal na política de combate às drogas do Estado de São Paulo, analisa a relação entre o PRB e a IURD, frequentemente agitada com a pretensão de deslegitimar a ambos. Ao percorrer os pormenores da formação dos quadros do PRB, Gutierrez observa os esforços institucionais de legitimação a partir da preparação de seus quadros para operar com termos, categorias e expedientes não religiosos na efetuação política e legal de uma moral cristã.

O capítulo de Lílian Sales permite estimar o alcance que essas moralidades cristãs possuem na esfera pública brasileira: detendo-se sobre a controvérsia em torno da audiência pública convocada pelo Supremo Tribunal Federal e destinada a instruir a corte no julgamento das disposições legais sobre pesquisas com células-tronco embrionárias, analisa argumentos mobilizados por cada bloco de especialistas convidados, "pró-vida" e "pró-pesquisas". Apesar da tentativa de delimitação "científica" das discussões sobre o "início da vida", a qualificação dos especialistas apresentados em cada lado e a articulação categorial das exposições mostram o quanto diversos códigos e gramáticas sociais "não científicos" estruturaram as posições de cada bloco, ainda que tenham sido apresentadas de maneira técnica e secular.

Legitimar-se pela via da visibilidade pública pode ser decisivo para campos particulares do social, como visto no estudo de César Augusto Assis Silva. O autor oferece um panorama da militância surda no Brasil contemporâneo, ressaltando a presença originária de injunções do fenômeno religioso sobre o contexto da surdez: enquanto a ação pastoral católica tendia à oralidade, suas correspondentes protestantes assumiram fortemente a contraoralidade e a especificidade da linguagem surda como instrumentos da prática missionária. Controvérsia semelhante se desenvolveu 
no contexto da elaboração do vigente Plano Nacional de Educação, pois a perspectiva de inclusão escolar defendida pelo Governo Federal tendia a levar os alunos surdos a matricularem-se em escolas regulares, proposta duramente combatida pela militância surda, orientada para a permanência da educação em escolas bilíngues.

Eventualmente, as estratégias de visibilidade dependem da atuação simultânea de militantes em mais de um campo social. Milton Bortoleto, exemplificando essa contingência, observa a articulação de membros de religiões afro-brasileiras e do cristianismo neopentecostal no contexto da tipificação e registro de crimes contra a liberdade de culto na cidade do Rio de Janeiro, quando a depredação de objetos do terreiro Cruz de Oxalá por membros da Igreja Geração de Jesus Cristo, em 2008, ganhou projeção nacional. O campo afro-brasileiro, com o concurso de policiais civis ligados à Comissão de Combate à Intolerância Religiosa, consegue o primeiro indiciamento por "discriminação religiosa" no Estado. Embora estivesse em jogo a aplicação de um tipo penal agravado, a inovação é apresentada como simples procedimento técnico, uma "atualização de software" das delegacias fluminenses. Os jovens acusados no episódio e seu pastor, por outro lado, manifestam-se no sentido de ressignificar as leis seculares como antagônicas às leis divinas, e, num esforço que vai das redes sociais à beira da Avenida Atlântica, passam a brandir sua palavra de ordem: "Bíblia sim, Constituição não".

O texto de Henrique Fernandes Antunes analisa uma decorrência da urbanização de religiosidades amazônicas e técnicas de transe xamânico associadas: sua disciplina jurídica, particularmente, a proscrição de um dos princípios ativos da ayahuasca, em 1985. As organizações religiosas que utilizavam a ayahuasca, com o concurso do campo universitário brasileiro, pela enunciação no âmbito de parecer técnico, mobilizando ativamente as categorias alucinógeno e cultura, obtiveram, em 1987, a liberação do "uso ritualístico" da ayahuasca. Cientes da fragilidade desses ganhos, esses atores buscaram, pelas décadas seguintes, retirar a ayahuasca do campo semântico dos entorpecentes e caracterizá-la nos campos religioso e cultural, culminando com a proposta de tombamento apresentada ao Instituto do Patrimônio Histórico e Artístico Nacional em 2008, e cuja manifestação é esperada como próxima fase dessa controvérsia.

A presença do campo acadêmico nas controvérsias públicas do fenômeno religioso no Brasil apresenta-se também na figura de Dário Neto, sujeito focal da análise de Aramis Luis Silva. No âmbito da controvérsia em torno das homoafetividades, reavivada na esfera pública brasileira pelo Papa Francisco em declarações dadas após celebrar, no país, a Jornada Mundial da Juventude, em 2013, Silva percorre as imbricações entre as vocações religiosa, política e acadêmica na constituição de Dário como militante cristão e homossexual. Silva conclui que as chamadas igrejas inclusivas renovam a temática dos Direitos Humanos e das teologias contra-hegemônicas, inscrevendo a sexualidade humana como fator decisivo em batalhas políticas e espirituais.

O pastorado desenvolvido pela IURD junto às mulheres é objeto da análise de Jacqueline Moraes Teixeira, que descreve as tecnologias, pedagogias e dispositivos mobilizados para a produção da "mulher virtuosa". Mobilizando as esposas dos mem- 
bros mais influentes de sua hierarquia, a IURD organiza a ação pastoral para mulheres desde a disposição das liturgias até as novas tecnologias de informação e comunicação, sobre as quais se articula o projeto Godllywood. Teixeira conclui que o corpo feminino é apresentado sistematicamente como instrumento de reprodução física e moral da família, por cuja contrição seria possível aceder à prosperidade como promessa divina. A etnografia de José Edilson Teles desloca a atenção dos grandes atores do campo evangélico aos mais modestos entre eles, especificamente, à peculiar condição das pequenas igrejas pentecostais, confrontadas com uma dimensão específica de legitimação. Após recepção pelo pastor José Ribamar, Teles analisa a trajetória daquele sacerdote e as dificuldades que a Igreja Manjedoura de Cristo enfrentava. Entre lógicas de denúncia e justificação, delineia-se um processo de produção social das pequenas igrejas: a experiência de seus sacerdotes passaria pela ideia de revelação, com sua necessidade decorrente de cisma, da fundação de uma nova igreja, com novos ministros, também sujeitos a essa mesma dinâmica, eventualmente. Negociar o reconhecimento público da própria sinceridade, do agir pelo Espírito, e não por vaidade pessoal, é o desafio, místico e político, de cada vaso rebelde.

Os dois últimos estudos buscam explorar os entremeios das noções de denúncia e abuso espiritual. Asher Brum analisa o desenvolvimento da denúncia de Antônio Carlos Brolezzi a respeito dos abusos que teria sofrido durante o período em que militara entre os numerários do Opus Dei. Paula Montero reúne outro conjunto de casos, mirando à própria constituição da noção de abuso espiritual no campo religioso brasileiro. As formas de governo eclesiástico, as estratégias de legitimação social de igrejas e sacerdotes e a crise da confiança entre pastores e rebanhos são efeito de um mesmo processo, por meio do qual ambos aprendem a movimentar-se entre as tensões de responsabilidades recíprocas.

A obra, ao tomar como eixo teórico e temático a noção de controvérsia, se afasta decisivamente do paradigma do sincretismo, outrora mobilizado como metanarrativa da religiosidade brasileira e de sua integração ao conjunto da vida civil. $O$ que desvela é uma dinâmica de ocupação da esfera pública pelo campo religioso, que atinge novas configurações diante do recuo da hegemonia católica: são os tempos da controvérsia, erigida em mandamento novo, irreversível, mesmo quando se promete o horizonte da reconciliação. Dessa maneira, a obra será decerto valiosa para além dos estudos do fenômeno religioso, pois mesmo sob essa mirada específica, contribui para a compreensão das mudanças decisivas que se anunciam ao país.

\section{Júlio Bizarria}

Doutorando no Programa de Pós-graduação em Memória Social da Universidade Federal do Estado do Rio de Janeiro (Unirio), membro do Observatório do Patrimônio Religioso do Estado do Rio de Janeiro. 